\title{
A Literature Review on Technologies in Future Small-scale Intelligent Manufacturing Systems
}

\author{
Tanja Kerezovic, and Gabor Sziebig, Member, IEEE
}

\begin{abstract}
Emergence of global markets forces businesses to become more flexible and adaptive to constantly changing demands and environments. In order to do so, enterprises turn towards application of newest technologies in manufacturing in order to make them intelligent. Since Small and Medium Enterprises play the central role in the domain of European manufacturing, the question arises - based on their limitations, how will SMEs succeed in adapting themselves to the change? This paper introduces and defines the term Small-scale Intelligent Manufacturing System (SIMS) and investigates the technologies that would enable such system to, not only survive, but compete on the future global scale.
\end{abstract}

\section{INTRODUCTION}

Small and Medium Enterprises (SME) play an important role in domestic manufacturing. The development of information technology has provided a platform for SMEs to participate in the global economy, but unlike the large-scale enterprises, SMEs face unique challenges because of their constraints in the terms of the size and budget [1]. Some SMEs, like manufacturing companies in Northern Peripheral Area (NPA), face additional challenge of geographical isolation from major markets.

SMEs in NPA region can only compete with utilization of advanced production processes against other competitors, as competition on solely price is not an option due to high labor cost. SMEs, which is the most common size in NPA perspective (in generally also in Europe), in order to survive in today's rapid changing market they are improving and enhancing the competitiveness and sustainability with application of the newest technologies [2].

These strategical decisions can also be found in the European Union's main Key Enabling Technologies in preparation for the challenges of the future, where Advanced Manufacturing is the most important one [3]. Advanced manufacturing technologies (like advance production processes, see Fig. 1.) are projected to have the highest influence on all other technologies. It will contribute to modernize manufacturing, reduction of cost on production with minimizing waste, pollution and production time.

For large-scale enterprises battle with these problems is a fair one, since they have the resources and ability to cope with them. But on the other hand, small and mediumenterprises lack the resources in terms of personnel, finances and as said, sometimes have unfavorable geographic location.

Tanja Kerezovic is with the Department of Industrial Engineering, UiT The Arctic University of Norway, Narvik, Norway (e-mail: tanja.kerezovic@uit.no).

Gabor Sziebig is with Department of Industrial Engineering, UiT The Arctic University of Norway, Narvik, Norway (phone: +47 7696-6323; email: gabor.sziebig@uit.no).
In [4] it is argued that in order to make themselves competitive in the market, small-scale manufacturers have to design their production to have a high degree of flexibility and to rely on state-of-the-art manufacturing technologies. Especially in high-wage countries, like Norway, improving flexibility, productivity and cost efficiency of the manufacturing system is of utmost importance.

Figure 1. Key Enabling Technologies [3]

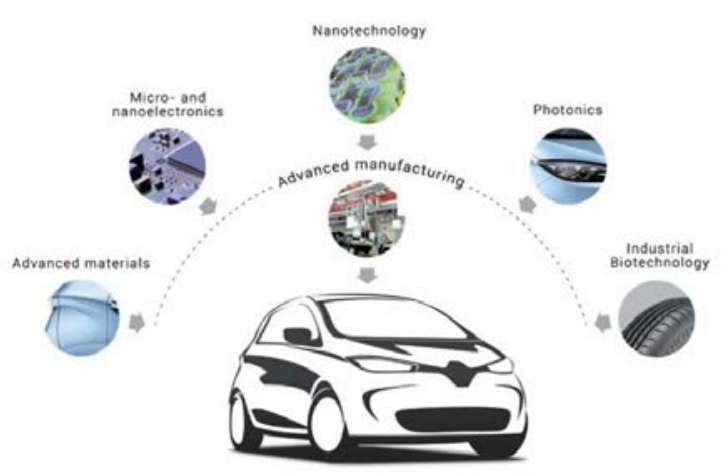

The application of intelligence in order to improve the efficiency and effectiveness of manufacturing systems has been a topic of numerous discussion in the engineering literature over the years [5]. Nowadays, the number of intelligent systems in manufacturing is increasing. According to [6] there are two main reasons for that:

- First one is market driven: customers demand more diversity of the products and shorter lead times.

- Second one is technology driven: increased availability of new electronic components is spurring the technology development.

The main focus in the field of manufacturing in SMEs has been the field of CIM, virtual design, remote programming and monitoring of machines and robots. But the introduction of CIM to SMEs did not go as well as expected. In most cases, only parts of CIM were fully integrated since CIM systems implicate complex structures, high investments which SMEs usually cannot afford [7].

Intelligent systems developed so far have been mainly designed for large-scale enterprises, and required great investments. Thus, SMEs face great obstacle when trying to design and implement intelligence in manufacturing. Since the focus now and toward the future, according to [6], is the distributed manufacturing through decentralization and implementation of artificial intelligence in every area of life, including manufacturing, this paper will focus on the investigation of technologies based on decentralization and 
implementation of artificial intelligence in manufacturing in the scope of SMEs. Additionally, since the term Small-scale Intelligent Manufacturing System (SIMS) is relatively new, the paper searches for the definition of the term.

In the next chapter through literature review main terms of SMEs, intelligence and intelligent manufacturing systems (IMS) are defined in order to reach the definition of the SIMS.

Chapter Existing Technologies addresses the existing as well as emerging technologies explored by today's IMS.

In the Discussion chapter, previously explained technologies are analyzed from the SMEs point of view in order to decide which technologies could be applied in the future SIMS.

\section{LITERATURE REVIEW}

\section{A. Small and Medium-enterprises (SME)}

According to latest European Commission [9] definition: "small enterprises are defined as enterprises which employ fewer than 50 persons and whose annual turnover or annual balance sheet total does not exceed 10 million euros." Where: medium enterprises are defined as "enterprises which employ fewer than 250 persons and whose annual turnover sheet is less than 50 million euro or annual balance sheet total does not exceed 43 million euros."

It is well known that SMEs play a crucial role in the economic development of every country (also shown in Fig. 2.). According to [10] SME's have restriction factors, precisely because of their characteristics. Those are:

Figure 2. Number of enterprises, persons employed, gross value added and the share of SMEs, 2012 [10]

\begin{tabular}{|c|c|c|c|c|c|c|}
\hline & Enterprises & & FTE & & GVA & \\
\hline & Total & $\%$ SME & Total & $\%$ SME & Total & $\%$ SME \\
\hline EU28 & 22346729 & 99.8 & 133767348 & 67.0 & 6184825 & 57.5 \\
\hline Belgium & 566006 & 99.8 & 2718355 & 70.1 & 189086 & 62.2 \\
\hline Bulgaria & 312608 & 99.8 & 1872997 & 75.5 & 18246 & 62.3 \\
\hline Czech Republic & 1007441 & 99.9 & 3521520 & 69.8 & 84142 & 56.0 \\
\hline Denmark & 213358 & 99.7 & 1602105 & 65.0 & 119936 & 62.5 \\
\hline Germany & 2189737 & 99.5 & 26401395 & 62.5 & 1385501 & 53.3 \\
\hline Estonia & 58408 & 99.7 & 393545 & 78.1 & 9338 & 74.9 \\
\hline Greece & 726581 & 99.9 & 2198986 & 86.5 & 54703 & 72.8 \\
\hline Spain & 2385077 & 99.9 & 10923323 & 73.9 & 434156 & 63.0 \\
\hline France & 2882419 & : & 15495621 & : & 890597 & : \\
\hline Croatia & 148573 & 99.7 & 1002905 & 68.3 & 19115 & 54.8 \\
\hline Italy & 3825458 & : & 14715132 & : & 646476 & : \\
\hline Cyprus & 46139 & 99.9 & 224915 & : & 7864 & : \\
\hline Lithuania & 141893 & 99.8 & 835630 & 76.2 & 12155 & 68.5 \\
\hline Latvia & 91939 & 99.8 & 573580 & 78.8 & 9269 & 69.2 \\
\hline Luxembourg & 29265 & 99.5 & 242533 & 68.3 & 19250 & 70.7 \\
\hline Hungary & 528519 & : & 2430681 & : & 46497 & : \\
\hline Malta & 26796 & 99.8 & 119224 & 79.3 & 3548 & 74.9 \\
\hline Netherlands & 862697 & 99.8 & 5359446 & 66.7 & 310022 & 62.9 \\
\hline Austria & 308411 & 99.7 & 2671477 & 68.0 & 164976 & 60.5 \\
\hline Poland & 1519904 & 99.8 & 8326839 & 68.9 & 171627 & 50.1 \\
\hline Portugal & 793235 & 99.9 & 2942895 & : & 66360 & : \\
\hline Romania & 425731 & 99.6 & 3837868 & 66.4 & 48432 & : \\
\hline Slovenia & 119644 & 99.8 & 574479 & 72.3 & 17140 & 62.8 \\
\hline Slovakia & 398392 & 99.9 & 1417228 & 69.7 & 32922 & 60.5 \\
\hline Finland & 226373 & 99.7 & 1457599 & 63.0 & 86957 & 59.6 \\
\hline Sweden & 661822 & 99.8 & 3025006 & 65.4 & 210859 & 58.5 \\
\hline United Kingdom & 1703562 & 99.7 & 17784620 & 53.0 & 1037293 & 50.9 \\
\hline Norway & 278899 & 99.8 & 1510838 & 67.6 & 230661 & 58.6 \\
\hline
\end{tabular}

Figure 3. Problem solving approach [11]

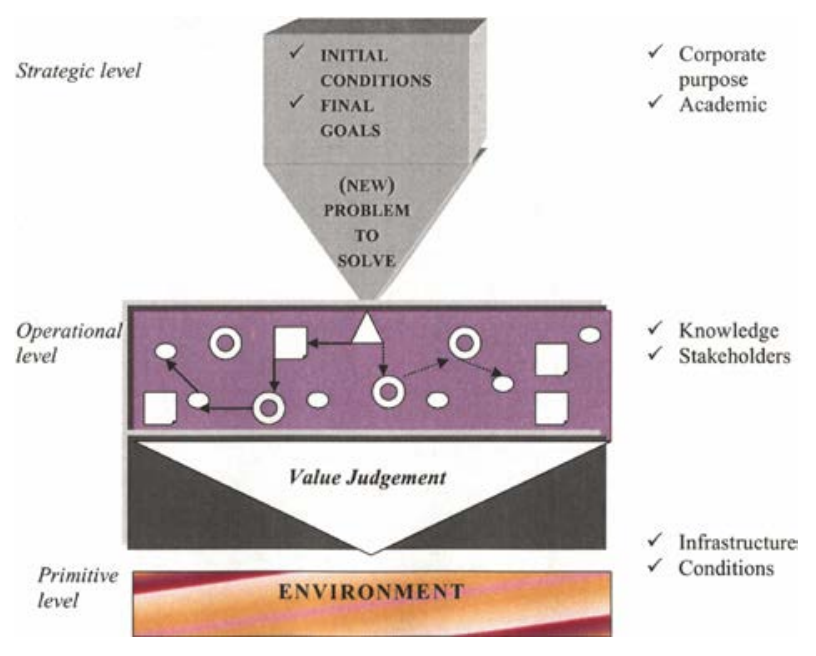

- Scale restriction

- Economic condition restriction

- Technical restriction

- Talented person restriction

- Geographical restriction

\section{B. Intelligence}

There exist multiple definitions of the intelligence. According to Oxford dictionary, intelligence is ,the ability to acquire and apply knowledge and skills". This definition is addressing two crucial aspects of intelligence: the ability to acquire needed knowledge and skills, and to use them accordingly.

Reference [11] explains that the intelligence is associated with abilities affiliated with problem solving, communication and learning capabilities and that the adaptation is probably the most important attribute concerning intelligence, and the common factor in all intelligence definitions.

However, the definition suggested by this paper is that intelligence is the ability to acquire and apply knowledge and skills in order to reach ones objectives and the ability to adapt its behavior to do so (see Fig. 3.).

\section{Intelligent Manufacturing Systems (IMS)}

Term system describes set of things or elements that are working together as a part of a mechanism with a specific purpose. This could be set of machine components, set of machines, living organism, etc.

Term manufacturing is defined as "making of goods or wares by manual labor or by machinery". 
If the term intelligent is added to the previous two definitions, it can be deducted that intelligent manufacturing system is a manufacturing system that is able to communicate with the environment in order to acquire the needed data and adapt its behavior accordingly, which means: make decisions based on the collected and previously stored data and ultimately, learn from the experience.

\section{Small-scale Intelligent Manufacturing Systems (SIMS)}

Based on the previous discussion and given definitions, the definition for SIMS proposed by this paper is:

Small-scale intelligent manufacturing system is a manufacturing system employed in SME that is able to autonomously acquire knowledge and skills, and to apply gathered knowledge and skills in order to adapt its behavior to reach the system's objective.

\section{EXISTING TECHNOLOGY}

As is already known, machines today have great capacity for collecting, storing, processing and distributing data. They receive this data through sensors and store it in their own or network memory. But so far, they don't have the intelligence to make the connection between different data in the memory and make decisions based on the conclusions. The topic of many discussions over the years is the application of intelligence in manufacturing system in order to improve their effectiveness and efficiency. But the extreme thinking of "unmanned factory" where robots and automation would take over the manufacturing has, up-to-date, shown that systems like that are too rigid and expensive. In order to break down that rigidity and complexity, inspiration has been found in many technological systems like robotic systems, software engineering systems, etc. where the system is decomposed into smaller, more manageable entities. These entities behave like mini-system on their own, but can also be coordinated as a sub-systems of a bigger, central system [5].

In order to design future intelligent manufacturing systems, some concepts have been developed over the years. But the most promising and the ones that have been discussed the most are:

\section{- Genetic Algorithms}

- Bionic manufacturing

- Holonic manufacturing system

- Agent-based manufacturing

\section{A. Genetic algorithms}

Genetic algorithm is a search method that is based on natural selection and mimics the natural evolution process. Just like the evolution, the algorithm proceeds in steps that are called generations. In order to reach the optimal solution, in each of the generations the algorithm creates new population of possible solutions (individuals) based on the old population and evaluated solutions up to that point [12]. It one way of introducing intelligence in manufacturing processes (Fig. 4.).

\section{B. Bionic manufacturing}

As the word itself says, bionics is the application of systems and methods observed in nature in order to generate
Figure 4. Multi-agent architecture with genetic algorithms [12]

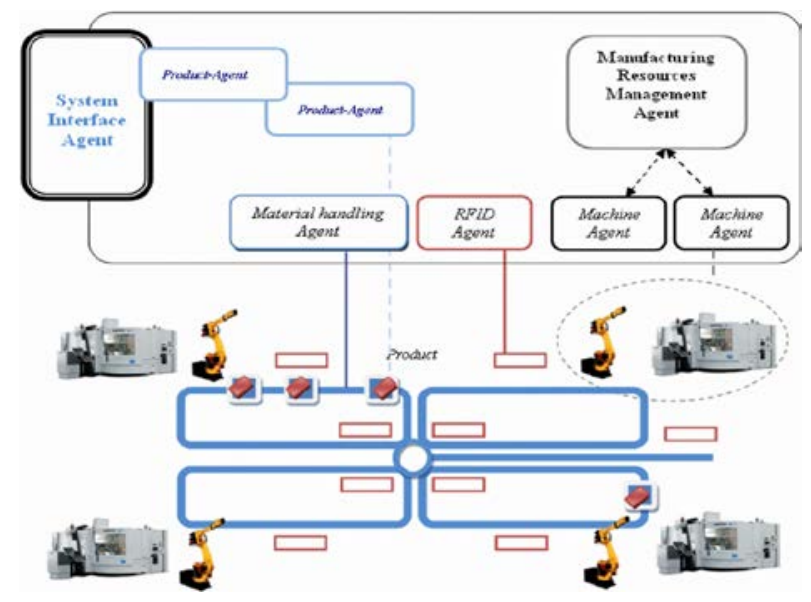

new technology systems. In [7] the parallel has been drawn between biological cells and manufacturing cells, since both are a part of a bigger organism/mechanism. The same way that cells regulate the chemical process within themselves and change the chemical information with environment, the production cells change its states in order to achieve the goal of the system. It represents a possible architecture of an intelligent manufacturing system.

\section{Holonic manufacturing system}

The term holon in holonic approach has been defined as something that is at the same time whole (complete) because it is constituted of other holon units, as well as a part (fragment) of something bigger, [13] cited in [5], [7].

As it is described in [5], a holonic system can be considered a system that is composed of scalar chains of holonic entities. At each level of this system entities can be viewed as a part of higher level system as well as to see that they, too, are built from sub-systems. This holonic architecture has been described through object-oriented programming in software design, where each object is an independent data set, and still a part of the entire software.

Some of the basic features exhibited by the holonic systems are:

- Relative autonomy of the holons - holons need to have the capacity of collecting their own data, ability to draw conclusions based on the data, and to have a mechanism for learning.

- System independence - as previously said, holons need to have relative autonomy, which means that they are required to be autonomous within given constraints. Thus, the control system gives each holon a task to perform, and the holons decide by themselves how to solve the task based on the gathered data and procedures and protocols installed in them.

- System flexibility - the adaptation of the system is made through individual holons, where they make individual adjustments to accomplish overall objective of the system. 


\section{Multi-agent system}

Concept of agent is derived from artificial intelligence. The term itself has not been defined yet, but it is known that it can be a person, a machine, piece of software or something else. The definition of an agent is offered in [14], where it is said that an agent is ,a software object that is capable of communicating with other agents". He explains that intelligent agents have the ability to reason, learn, negotiate and thus, behave as an intelligent entity (see comparison in Fig. 5.). In reference [15] it is considered that an agent is ,the object that could finish the given task independently without people's interference."

Agent are usually autonomous, which means that they are not controlled or managed neither by a human being nor by other software. They possess knowledge about other agents in the system as well as their environment and are able to communicate and interact with agents in the system, as well as with external systems. Each of the agent has its own set of goals and motivations, but in multi-agent system apart from this, agents have an overall goal and have to work together to complete it [15].

In order to be regarded as intelligent, an agent should possess:

- Autonomy - to be able to complete tasks without external interference (human or software),

- Adaptability - to be able to perceive the environment and adapt to it accordingly,

- Coordination - in multi-agents system, agents should be able to coordinate among themselves to complete a task.

Input to MAS (multi agent system) is a global task. The software of the system divides the task into sub-tasks, where each of the agents work on a specific sub-task and cooperate with other agents in order to reach the goal [16].

\section{DISCUSSION}

Based on the given definitions and existing technologies for IMS, this chapter discusses the technologies that can be used by SMEs. Until now the focus in the field of manufacturing in SMEs has been the field of CIM, virtual design, remote programming and monitoring of machines and robots. But as previously explained, the introduction of CIM was not entirely successful to SMEs where only parts of CIM were fully integrated. According to [8], the focus now

Figure 5. Conventional vs Multi-agent manufacturing control system [7]

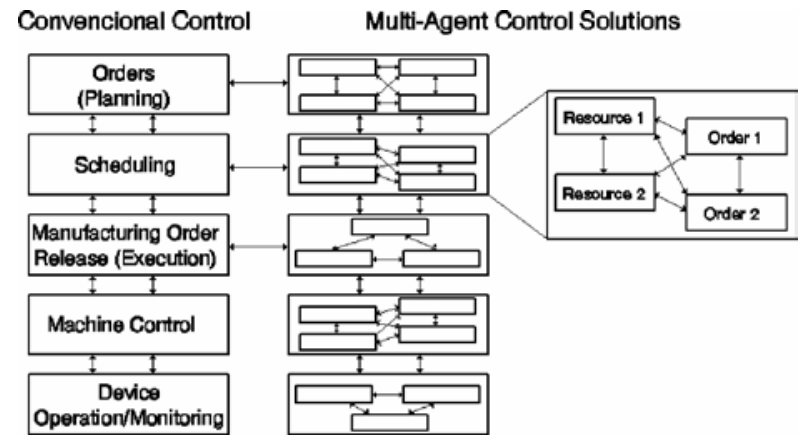

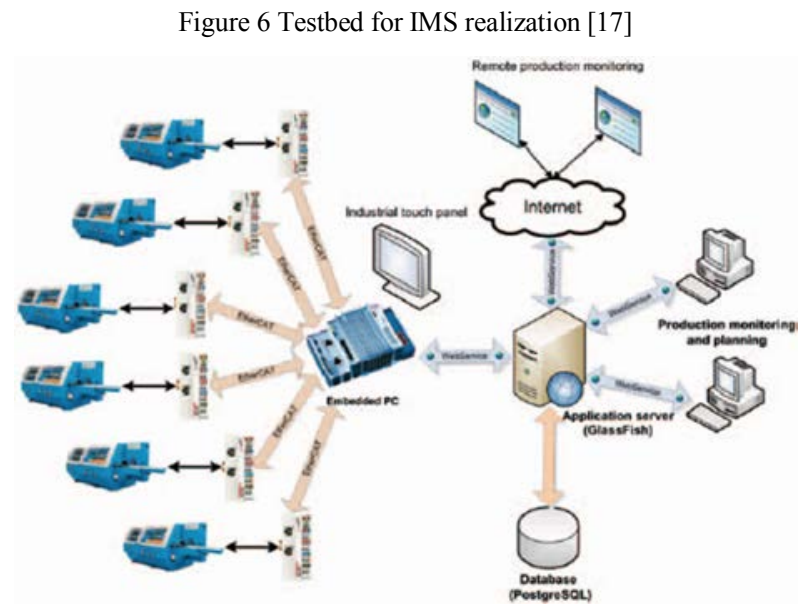

and toward the future are new generation robots that support human-robot collaboration, additive manufacturing in the area of 3D manufacturing, distributed manufacturing through decentralization of manufacturing and implementation of artificial intelligence in every area of life, including manufacturing.

In [16] it is argued that the future role of European SME's is closely related to research in the areas of,,intelligent, open, modular and low cost systems". He argues that Holonic Manufacturing Systems present the architecture of the future intelligent SME's.

Reference [17] states that a promising organizational structure for the future IMS is a composition of distributed and autonomous units that would cooperate in order to reach a specific goal. Based on the research presented in [17] it is stated that ,an agent based software is designated as technology for industrial IMS realization, regardless of the chosen organizational architecture". In the same reference it is argued that based on their conceptual similarities, combination of holonic manufacturing system architecture with multi-agent software technology is currently the most „promising basis for industrial implementation of IMS” (see Fig. 6.).

Thus, if the SMEs want to be competitive in the future, they have to try to implement these technologies and apply these approaches. Undoubtedly, the future of SMEs will lie in their ability to implement artificial intelligence, where multiagent systems through holonic or some other system architecture present the biggest opportunity so far.

Since one of the main constraints of SMEs is financial resources, this approach may for now require great investments for R\&D. But the agent technology presents a great opportunity to make every manufacturing, small or large-scale, intelligent, thus it is not just a question of SMEs. Thus if the agents would be designed and produced globally, and made to be modular: be developed so that the enterprise buys finished agent and calibrates them to fit the specific machine or a function, it presents a great opportunity for SMEs to compete on global market.

Another aspect is the introduction of industry 4.0 to SMEs. The concept of industry 4.0 was to develop from 
Figure 7. The four stages of the Industrial Revolution [19]

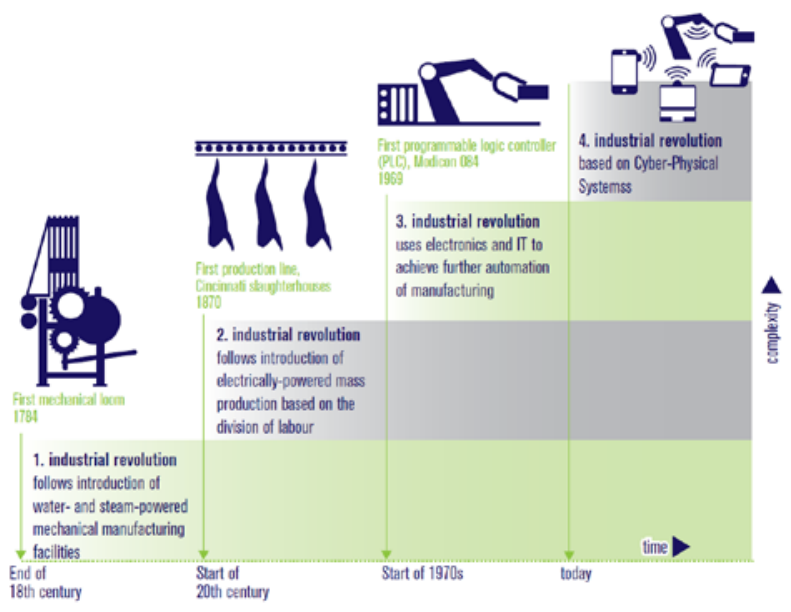

Internet of Things, which was created by British technology pioneer Kevin Ashton in 1999 [18]. Then in April 2013, the Industry 4.0 Working Group present a final report to the German federal government. The report categorizes human industry into four stages, from steam engine stage - first industrial revolution, electrically-powered mass production stage - second industrial revolution and electronicsinformation stage - third industrial revolution, to cyberphysical based production stage - fourth industrial revolution [19] as shown in Fig. 7. The fourth stage is the Industry 4.0 which includes cyber-physical system, Internet of things and cloud computing [20]. As for now, we are in the industrial revolution but not finish this revolution. Germany is planning to promote the revolution process and Germany is not the only country planning to upgrade their industry. The industry upgrading becomes a trend across the world recently, the representative countries' plan including:

- Japan - Super Smart Society [21],

- Norway - Norge 6.0 [22],

- United States - The Advanced Manufacturing Partnership [23],

- China - Made in China 2025 [24].

An SME with incorporating the methods of the Industry 4.0 along with state-of-the-art technologies and leading edge management methods can achieve continuous improvement on flexibility, reliability, productivity and sustainability of manufacturing system in order to provide customers with high customized products at reasonable price and rapid delivery.

\section{CONCLUSION}

This paper defines the term Small-scale Intelligent Manufacturing System, as well as terms related to it. It also sheds light and gives insight into technologies that are not necessarily used in SME manufacturing, but from which SIMS might benefit. The concepts and ideas of such technologies usually come from different fields, but could be adopted and adjusted to fit SIMS. As explained, the most promising technology is multi agent systems technology, which is based on application of artificial intelligence. The possible problems of introducing agent technology in SIMS are mentioned, but possible solutions are offered and discussed in order to reduce cost and complexity of applications of such technologies.

Suggestion for the further research is to investigate the feasibility of modular agents. Case studies on implementation of MAS and other listed technologies to SIMS should be conducted.

\section{ACKNOWLEDGMENT}

The research was supported by the TARGET Project, which is supported by the European Union Northern Peripheries and Arctic (NPA) Programme under Priority 1: Innovation, Research and Technology Development. The NPA Programme has been established to help peripheral and remote communities on the northern margins of Europe to develop their economic, social and environmental potential.

\section{REFERENCES}

[1] N. Ahmad and R. G. Qiu, "Effectiveness Evaluation Services for Small to Medium-Sized Manufacturing Enterprise," 2006.

[2] SINTEF Report A27222, Effects of technological changes for the Norwegian industrial- and labor-sector (In Norwegian), 2015

[3] European Commission High Level Expert Group on Key Enabling Technologies Final Report, 2015

[4] F. Klocke, K. Arntz and D. Heeschen, "Decision-Making Process in Manufacturing Technology Planning for Small Scale Productions," in International Conference on System Science, Hawaii, 2014.

[5] J. Mathews, "Organizational foundations of intelligent manufacturing systems - the holonic viewpoint," Computer Integrated Manufacturing Systems, vol. 8, pp. 237-243, 1995.

[6] A. Cannata, M. Gerosa and M. Taisch, "SOCRADES: a Framework for Develoing Intelligent Systems in Manufacturing," pp. 1904-1908, 2008.

[7] C. Christo and C. Cardeira, "Trends in Intelligent Manufacturing Systems," pp. 3209-3214, 2007.

[8] B. Meyerson, "Top 10 emerging technologies of 2015," 4 March 2015. [Online]. Available: http://www.weforum.org/. [Accessed 19 September 2015].

[9] E. C. The new SME definition - User guide and model declaration, 2005.

[10] L. Chunquan and Z. Dejian, "Study on small and medium enterprises collaborative manufacturing system based on agency organization services," in International Technology and Innovation Conference, 2006.

[11] I. Dumitrache and S. I. Caramihai, "Towards a New Generation of Intelligent Manufacturing Systems," in 4th International IEEE Conference "Intelligent Systems", 2008.

[12] M. Gaham and B. Bouzouia, "Intelligent Product-Driven Manufacturing Control," 2009.

[13] A. Koestler, in The Ghost in the Machine, 1967.

[14] G. Rzevski, "A frameworks for designing intelligent manufacturing systems," Computers in industry, pp. 211-219, 1997.

[15] Q.-1. Guo and M. Zhang, "An agent-oriented approach to resolve scheduling optimization in intelligent manufacturing," Robotics and Computer-Integrated Manufacturing, pp. 39-45, 2010.

[16] P. Kopacek, "Intelligent Manufacturing: Present State and Future Trends," Journal of Intelligent and Robotic Sytems, no. 26, pp. 217$229,1999$.

[17] T. Zabisnki and T. Maczka, "Human System Interface for Manufacturing Control - Industrial Implementation," Rzeszow, 2010.

[18] Werr P. IoT Evolution World, 2015.

[19] Kagermann H, Wahlster W, Helbig J. Final report of the Industrie 4.0 Working Group, 2013.

[20] Morgan J. A Simple Explanation Of 'The Internet Of Things' 
[21] Harayama Y. Society 5.0, 2016.

[22] Qvam W. Norge 6.0, 2016.

[23] The White House Office of the Press Secretary. President Obama Launches Advanced Manufacturing Partnership Steering Committee "2.0", 2013.

[24] Wübbeke J, Meissner M, Zenglein MJ, Ives J, Conrad B. MADE IN CHINA 2025: The making of a high-tech superpower and consequences for industrial countries, 2016. 